\title{
Derecho a la nacionalidad y prevenir la apatridia en los países de la región
}

\section{Comisión Interamericana de Derechos Humanos}

No. $042 / 19$

$25 / 02 / 19$

Washington, D.C. - La Comisión Interamericana de Derechos Humanos (CIDH) saluda las medidas adoptadas por Chile, Colombia, Haití, Panamá, Paraguay y Uruguay para garantizar el derecho a la nacionalidad. La CIDH llama a los Estados a seguir adoptando medidas dirigidas a garantizar el goce efectivo del derecho a la nacionalidad, así como a prevenir y erradicar la apatridia en la región.

El 16 de enero de 2019, entró en vigor en Panamá el Decreto Ejecutivo 10 del 16 de enero de 2019, a través del cual se otorga protección a las personas apátridas en el país y la posibilidad de optar por la naturalización. La adopción de este Decreto posiciona a Panamá en el conjunto de países que han dado pasos significativos hacia la erradicación de la apatridia en las Américas.

En el mismo sentido, el 7 de noviembre de 2018, entró en vigor en Uruguay la Ley 19.682 sobre Reconocimiento y Protección al Apátrida. Esta ley incluye la adopción de un proceso de determinación de la condición de apátrida en un máximo de 270 días y es la segunda ley de la región especializada en la materia.

Por su parte, el 19 de septiembre de 2018, entró en vigor en Paraguay la Ley Número 6.149 de Protección y Facilidades para la Naturalización de las Personas Apátridas. La referida ley es la primera en la región en abordar este tema de manera especializada mediante una legislación. La ley establece un procedimiento a cargo de la Comisión Nacional de Refugiados para identificar y proteger a las personas apátridas en un plazo de 180 días y permite resolver la situación de estas personas a través de un trámite de naturalización. Asimismo, la CIDH destaca la importancia del establecimiento de un procedimiento para la 
inscripción tardía de nacimientos en la ley, así como la inclusión de la cláusula que permite el acceso a la nacionalidad paraguaya, a través de consulados y embajadas, para hijos de personas paraguayas nacidas en el extranjero que por disposiciones legales de su país de nacimiento resultaren apátridas.

Asimismo, Haití y Chile formalizaron su adhesión a la Convención sobre el Estatuto de los Apátridas de 1954 y a la Convención para Reducir los Casos de Apatridia de 1961, al depositar los instrumentos oficiales ante la Secretaría General de las Naciones Unidas en Nueva York. Haití lo hizo el 27 de septiembre de 2018 en el marco de la Asamblea General de las Naciones Unidas en Nueva York. Chile, por su parte, depositó los instrumentos el 11 de abril de 2018. La adopción de estas convenciones complementa los marcos jurídicos nacionales para facilitar el acceso a la nacionalidad de las personas y ofrecer protección a las personas que ven obstaculizado el acceso a dicho derecho.

Como antecedentes destacables, el 4 de abril de 2018, la Corte Constitucional de Colombia publicó en su página oficial la Sentencia T-023/18 de 5 de febrero de 2018 sobre derecho a la nacionalidad de los niños y las niñas, mediante la cual ordenó a la Registraduría a inscribir el nacimiento extemporáneo de una niña sin exigir el requisito de apostilla, siempre y cuando la persona acuda con un mínimo de dos testigos que den fe del nacimiento. Dicha sentencia se encuentra acorde con otros desarrollos que han tenido lugar en Colombia, entre los cuales destaca la Circular Número 168 emitida el 22 de diciembre de 2017 por la Registraduría Nacional del Estado Civil de Colombia, a través de la cual se mandata la inscripción en el registro civil de nacimiento de los hijos de extranjeros nacidos en Colombia a los cuales ningún Estado les reconozca la nacionalidad, sin requerir la prueba de domicilio. De tal forma, Colombia adoptó medidas para garantizar el registro de nacimientos y facilitar el acceso a la nacionalidad de personas que, de otra forma, se encontrarían en riesgo de apatridia.

"Las medidas adoptadas por Panamá, Uruguay, Haití, Paraguay, Chile y Colombia denotan el compromiso de dichos Estados frente a la importancia de garantizar el derecho a la nacionalidad y de prevenir y erradicar la apatridia en las Américas. Con estas medidas, sumamos seis países a la reciente puesta en 
marcha de acciones encaminadas a contar con marcos jurídicos que garanticen el goce efectivo del derecho a la nacionalidad para todas las personas en la que la región y se suman a las medidas que ya venían siendo implementadas por México, Costa Rica, Ecuador y Brasil”, dijo el Comisionado Luis Ernesto Vargas Silva, Relator sobre los Derechos de los Migrantes de la CIDH.

A su vez, "un factor que desde la Comisión se considera relevante es que muchas de estas medidas han sido el resultado de sinergias y esfuerzos conjuntos entre autoridades estatales, diversas organizaciones de la sociedad civil, entre los que se encuentran la Red de las Américas sobre Nacionalidad y Apatridia (Red ANA), el Alto Comisionado de las Naciones Unidas para los Refugiados (ACNUR) y la misma CIDH", agregó el Relator.

Teniendo en cuenta los movimientos migratorios masivos que se vienen dando en la región durante los últimos años y en particular los desafíos que enfrentan en materia de derecho a la nacionalidad y derecho a la identidad los hijos de personas migrantes, la $\mathrm{CIDH}$ recuerda que con base en la jurisprudencia del Sistema Interamericano y las Observaciones Generales Conjuntas 3 y 4 del Comité de Protección de los Derechos de Todos los Trabajadores Migratorios y de sus Familias y 23 y 24 del Comité de los Derechos del Niño de Naciones Unidas, resulta fundamental garantizar que todos los niños al nacer sean inscritos inmediatamente en el registro civil y reciban certificados de nacimiento, cualquiera que sea su situación migratoria o la de sus padres. Asimismo, se debe garantizar el otorgamiento de la documentación que pruebe la nacionalidad, así como la existencia de marcos jurídicos que provean protección a las personas apátridas al establecer procedimientos para la determinación de la condición de apatridia y mecanismos que faciliten el acceso a la nacionalidad para dichas personas. La CIDH reitera su llamado a los Estados a seguir adoptando medidas que permitan garantizar el pleno acceso y goce del derecho a la nacionalidad, así como para la prevención y erradicación de la apatridia. 
